\title{
Geoconservação em Monumentos Naturais no Brasil
}

\author{
Geoconservation in Natural Monuments in Brazil
}

Milene Couto, Bacharelado em Ciências Ambientais, Universidade Federal do Estado do Rio de Janeiro, Brasil, milene_couto@hotmail.com

(1) https://orcid.org/0000-0002-8229-9194

Carlos A. Figueiredo, Departamento de Ciências do Ambiente, Universidade Federal do Estado do Rio de Janeiro, Brasil, carlos.figueiredo@unirio.br

(D) https://orcid.org/0000-0001-6331-518X

Resumo: Foi evidenciada a relevância da geodiversidade para a conservação da natureza através de um levantamento das unidades de conservação da categoria de Monumentos Naturais no Brasil. A fonte principal de dados foi o Cadastro Nacional de Unidades de Conservação - CNUC. O conceito de Monumento Natural foi analisado para o Brasil na literatura e em órgãos de proteção ao património, nomeadamente IPHAN, UNESCO e IUCN. Foram identificados 60 Monumentos Naturais no Brasil. A criação de Monumentos Naturais apresentou como principal motivação aspectos ligados à geodiversidade, algumas vezes associados à biodiversidade e/ou aspectos culturais. Muitos destes atributos estão relacionados a aspectos geomorfológicos que formam a paisagem e servem de estrutura para os biomas protegidos e a beleza cênica local. Frequentemente, mais de um tipo de feição geomorfológica ou atributo é encontrado em um mesmo Monumento Natural. Os elementos da geodiversidade que justificam os Monumentos Naturais brasileiros são: resquícios paleontológicos; maciços; cavidades naturais; serras; inselbergs; rios; lagoas; cânions; cachoeiras; falésias; dunas; e ilhas oceânicas. Os Monumentos Naturais possuem uma relação direta com a ideia de herança, ao se vincularem a aspectos geomorfológicos e culturais. O conceito de Monumento Natural na legislação brasileira deveria ser revisto para aproximar-se do conceito da IUCN que explicita componentes geológicos, culturais, espirituais e a associação com a biodiversidade local.

Palavras-chave: Unidade de conservação; Geodiversidade; Áreas protegidas; Categorias de proteção; Patrimônio natural.

Abstract: The relevance of geodiversity for nature conservation was evidenced by a survey of conservation units of the Natural Monument category in Brazil. The main source of data was the Cadastro Nacional de Unidades de Conservação - CNUC. The concept of Natural Monument was analyzed for Brazil in literature and heritage protection bodies, namely IPHAN, UNESCO and IUCN. We identified 60 Natural Monuments in Brazil. The creation of Natural Monuments presented as main motivation aspects related to geodiversity, sometimes associated with biodiversity and / or cultural aspects. Many of these attributes are related to geomorphological aspects that form the landscape and serve as a framework for protected biomes and local scenic beauty. Often, more than one type of geomorphological feature or attribute is found in the same Natural Monument. The geodiversity elements that justify the Brazilian Natural Monuments are: paleontological remnants; massifs; natural underground cavities; montain ranges; inselbergs; rivers; lagoons; canyons; waterfalls; cliffs; dunes; and oceanic islands. The Natural Monuments have a direct relation with the idea of inheritance, being linked to geomorphological and cultural aspects. The Natural Monument concept in Brazilian legislation should be revised to approximate the IUCN concept that evidences geological, cultural, spiritual components and the association with local biodiversity.

Keywords: Conservation unit; Geodiversity; Protected area; Protection category; Natural heritage. 


\section{Introdução}

A criação de territórios ou áreas protegidas ocorre desde a antiguidade devido a questões culturais, religiosas, esportivas e políticas. Porém, as primeiras áreas naturais contemporâneas institucionalmente protegidas surgiram no final do século XIX devido à grande expansão urbana, agrícola e industrial (Olivato, Gallo Jr, 2008). Desde então, o número de áreas protegidas vem aumentando consideravelmente e hoje a proteção de territórios é um dos principais instrumentos para conservação da herança natural remanescente no mundo.

O Parque Nacional de Yellowstone, localizado na Califórnia, Estados Unidos, foi a primeira área protegida contemporânea criada na forma de parque nacional, em 1872. Depois dele, vieram os parques nacionais no Canadá (1885), Nova Zelândia (1894), África do Sul (1898) e Austrália (1898). No Brasil, o primeiro Parque Nacional foi o de Itatiaia, criado em 1937, localizado na divisa dos estados do Rio de Janeiro e Minas Gerais. Em 1939, foram criados o Parque Nacional do Iguaçu, no Paraná, e o Parque Nacional da Serra dos Órgãos, no Rio de Janeiro (Bensusan, 2006).

A Constituição da República Federativa do Brasil de 1988 destaca em seu Art. 225, inciso III que o poder público tem o dever de: "definir, em todas as unidades da Federação, espaços territoriais e seus componentes a serem especialmente protegidos" (Brasil, 1988). Entre os "espaços territoriais especialmente protegidos" estão os territórios que, de acordo com a definição da Conveção de Diversidade Biológica (ONU, 1992) constituem áreas protegidas: "área geograficamente definida, que é destinada ou regulada e manejada para atingir determinados objetivos de conservação". Atualmente, áreas protegidas (sensu CDB) no Brasil são conhecidas como unidades de conservação (UC) e sua regulamentação é dada pela Lei $n^{\circ}$. 9.985, de 18 de julho de 2000, que instituiu o Sistema Nacional de Unidades de Conservação da Natureza (SNUC) (Brasil, 2000; Pereira, Scardua, 2008).

O SNUC (Brasil, 2000) apresenta 12 categorias de unidades de conservação. Estas categorias são distribuídas em dois grupos com concepções diferentes da forma de proteção dada aos ambientes naturais - Proteção Integral e Uso Sustentável. O grupo de Proteção Integral tem como objetivo "preservar a natureza, sendo admitido apenas o uso indireto dos seus recursos naturais" e é composto pelas seguintes categorias: Estação Ecológica, Reserva Biológica, Parque Nacional, Monumento Natural e Refúgio da Vida Silvestre. O Grupo de Uso Sustentável, prevê "compatibilizar a conservação da natureza com o uso sustentável de parcela dos seus recursos naturais", e é constituído pelas categorias: Área de Proteção Ambiental, Área de Relevante Interesse Ecológico, Floresta Nacional, Reserva Extrativista, Reserva da Fauna, Reserva de Desenvolvimento Sustentável e Reserva Particular do Patrimônio Natural.

Outro regulamento de interesse neste estudo que trata da temática de espaços territoriais especialmente protegidos é o Decreto-Lei $n^{\circ} 25$, de 30 de novembro de 1937 que, institui a proteção do patrimônio histórico e artístico nacional. 
As justificativas para criação de unidades de conservação, muitas vezes levam em conta além dos aspectos naturais de relevância (e.g. geodiversidade e biodiversidade), também aspectos culturais que se relacionam com a paisagem e atributos naturais. Desta forma, os espaços territoriais especialmente protegidos tombados como patrimônio, por vezes, se relacionam com áreas naturais protegidas. Neste sentido, a categoria Monumento Natural reflete especialmente a noção de patrimônio e torna este protegido através da Lei do SNUC (Brasil, 2000).

A Constituição Federal do Brasil (1988) e a Lei do Sistema Nacional de Unidades de Conservação da Natureza no Brasil (2000), ambas enfatizam a proteção da diversidade biológica, mas fazem pouca referência ao patrimônio geológico enquanto componente dos sistemas ecológicos. O SNUC, por exemplo, (cf. Brasil, 2000) menciona "diversidade biológica" 10 vezes e "biodiversidade" três vezes e dedica apenas um inciso à proteção do patrimônio geológico.

O objetivo deste trabalho é mapear Monumentos Naturais federais, estaduais e municipais no Brasil e identificar as justificativas para sua criação. Desta forma, evidenciar a relevância da geodiversidade para a conservação da natureza. Pretendemos ainda contribuir para a definição da categoria Monumento Natural através da análise dos objetivos teóricos da categoria em comparação com as definições de patrimônio natural em âmbito nacional e internacional.

\section{Metodologia}

Realizou-se uma pesquisa documental com o levantamento bibliográfico de publicações acerca do tema. As fontes de consulta utilizadas nesta pesquisa foram livros, dissertações, artigos científicos, sites governamentais e documentos legais, citados na seção referências desta monografia. O Cadastro Nacional de Unidades de Conservação on-line (MMA, 2019) foi a fonte primária de dados sobre as unidades de conservação da categoria Monumento Natural no Brasil. Características e os principais atributos de cada Monumento Natural foram obtidas nos documentos legais de criação e complementados em páginas eletrônicas de notícias ou governamentais sobre cada UC. Os documentos de criação foram obtidos pela Internet, seja na pesquisa direta em buscadores, seja via contato telefônico ou por email com secretarias estaduais e municipais. Os documentos federais estão disponíveis nas páginas do Ministério do Meio Ambiente ou do Governo do Brasil (2019).

O conceito de Monumentos Naturais do Brasil (Brasil, 2000) é relacionado com a categoria de área protegida III da International Union for Conservation of Nature (IUCN, 1994), organização internacional de maior representatividade em esforços de conservação da natureza. Ao se somarem as duas definições, fica evidente que a categoria em estudo pretende abranger aspectos culturais tanto quanto naturais, e por isso, foram também investigadas as definições de patrimônio histórico e artístico nacional do Instituto do Patrimônio Histórico e Artístico Nacional (IPHAN) e patrimônio mundial da humanidade da Organização das Nações Unidas para a educação, a ciência e a cultura (UNESCO) para entender o quanto os conceitos são complementares ou se reforçam mutuamente. 
O estudo é baseado nos dados do Cadastro Nacional de Unidades de Conservação - CNUC (Ministério do Meio Ambiente, 2019), consultado inicialmente em 14 de agosto de 2013 e atualizado em 12 de julho de 2019. Através de relatórios do CNUC é possível conhecer o número de unidades de conservação da natureza, seus documentos de criação, estados e municípios de abrangência, área total, existência de conselhos e planos de manejo e bioma onde se situam.

Para entender melhor a peculiaridade desta categoria de unidade de conservação no Brasil, foram analisados os estudos técnicos de criação, os documentos de criação e sites institucionais dos Monumentos Naturais brasileiros. A partir desta análise foi possível complementar dados como: localização, área, bioma protegido, ano de criação, os atributos que justificaram a criação de cada um e a finalidade de cada Monumento Natural.

A partir de uma revisão acerca dos principais aspectos que justificam a criação de Monumentos Naturais no Brasil, foi elaborada uma tabela com os principais atributos de cada Monumento Natural (Tabela I). Estes atributos foram divididos em três categorias: geodiversidade, biodiversidade e aspectos culturais. Foram atribuídas uma ou duas categorias para cada Monumento Natural e de um a três atributos principais. Na categoria de geodiversidade foram propostos 13 atributos; para biodiversidade foram propostos cinco atributos; e para aspectos culturais, propostos dois atributos. Cada Monumento Natural apresenta de um a três atributos principais. Devido ao fato de alguns monumentos naturais apresentarem mais de um atributo principal, o somatório do número de atributos é maior que o número de monumentos naturais.

Tabela I: Categorias e atributos utilizados na categorização dos Monumentos Naturais.

\begin{tabular}{|r|c|c|c|}
\hline Categorias & Geodiversidade & Biodiversidade & \multirow{2}{*}{$\begin{array}{c}\text { Aspectos Culturais } \\
\text { Fatos históricos }\end{array}$} \\
\hline Atributos & Resquícios arqueológicos & Espécies endêmicas & \multirow{2}{*}{ Lendas } \\
\hline & $\begin{array}{c}\text { Resquícios } \\
\text { paleontológicos }\end{array}$ & Espécies raras & \\
\hline & Cavidades naturais & Refúgio de espécies & \\
\hline & Inselbergs & & \\
\hline & Maciços & & \\
\hline & Serras & & \\
\hline & Canyons & & \\
\hline & Falésias & & \\
\hline & Cachoeiras & & \\
\hline & Dunas & & \\
\hline & Lagos e lagoas & & \\
\hline
\end{tabular}

Fonte: Documentos de criação de unidades de conservação da categoria Monumento Natural.

\section{Resultados}

Algo monumental tem um apelo de extraordinário e grandioso que pode ou não ser reconhecido, seja pelo Estado, seja pela sociedade. No Brasil, foram identificados dois tipos principais de reconhecimento oficial do que poderia ser chamado de monumento natural. O primeiro é a categoria de unidade de conservação - Monumento Natural - 
assim definida no SNUC. O segundo tipo de monumento é aquele que é especialmente protegido pelo seu valor enquanto patrimônio cultural ou natural. Em seguida, são apresentadas as definições de cada uma destas formas de reconhecimento.

\subsection{Monumento Natural como área natural protegida}

Os objetivos básicos da criação de unidades de conservação da categoria Monumentos Naturais em âmbito nacional são definidos através do SNUC e, em âmbito internacional, pela IUCN que possui uma categoria própria dedicada aos Monumentos Naturais, chamada Category III (IUCN, 1994). Na Tabela II, são apresentados os objetivos básicos dos Monumentos Naturais que constituem áreas naturais protegidas em âmbito nacional e internacional.

Tabela II. Conceito de Monumento Natural no Brasil e na IUCN (tradução livre).

\begin{tabular}{|l|l|}
\hline Instituto & Definição \\
\hline $\begin{array}{l}\text { Monumento Natural - SNUC (Lei } \\
9.985 / 2000 \text { - Art. 12; Brasil, 2000) }\end{array}$ & $\begin{array}{l}\text { Unidades de conservação de proteção integral que tem } \\
\text { como objetivo básico preservar sítios naturais raros, } \\
\text { singulares ou de grande beleza cênica. }\end{array}$ \\
\hline $\begin{array}{l}\text { Category III: Natural Monument or } \\
\text { Feature (IUCN,1994) }\end{array}$ & $\begin{array}{l}\text { Têm como objetivo prover a proteção de áreas naturais } \\
\text { excepcionais específicas, eventualmente aliadas a } \\
\text { componentes geológicos, culturais ou espirituais, e sua } \\
\text { associação com a biodiversidade local. }\end{array}$ \\
\hline
\end{tabular}

Fonte: SNUC (Lei 9.985/2000 - Art. 12; Brasil, 2000) e IUCN (1994)

\subsection{Monumento Natural como como Patrimônio Cultural e Natural}

A etimologia da palavra monumento tem origem no latim monumentum, que por sua vez deriva do verbo monere, que significa "advertir", "lembrar", ou seja, aquilo que traz algo à lembrança (Santiago, 2007). Primeiro chamados de antiguidades e depois de monumentos, as obras do passado só começaram a ser entendidas como patrimônio com a conceituação da história como disciplina (Delphim, 2004). Inicialmente, a concepção de "patrimônio" ou "patrimônio histórico" era definida apenas para bens materiais que recebiam alguma forma de reconhecimento oficial. Atualmente, o conceito de "patrimônio cultural" inclui até os bens de natureza imaterial, como por exemplo, as expressões orais e gráficas dos Wajãpis do Amapá, a Paisagem do Rio de Janeiro e o Samba de roda do Recôncavo Baiano (Sánchez, 2008; UNESCO, 2008).

No Brasil, o IPHAN é o órgão responsável pelo tombamento dos patrimônios históricos e artísticos nacionais. De acordo com o Decreto-Lei $n^{\circ} 25$, de 30 de novembro de 1937, consiste em patrimônio histórico e artístico nacional o "conjunto dos bens móveis e imóveis existentes no país e cuja conservação seja de interesse público, quer por sua vinculação a fatos memoráveis da história, quer por seu excepcional valor arqueológico ou etnográfico, bibliográfico ou artístico" (Brasil, 1937).

De acordo com a Constituição Brasileira de 1988, o patrimônio cultural brasileiro é constituído pelos "conjuntos urbanos e sítios de valor histórico, paisagístico, artístico, 
arqueológico, paleontológico, ecológico e científico" (Brasil, 1988). Desta forma, entende-se que a criação de um Monumento Natural pode ser motivada pelo valor cultural de determinado território ou feição geográfica (Alvarenga, 2009).

O tombamento de patrimônios naturais ou culturais pode ser realizado nas três esferas administrativas do Poder Público brasileiro. Além do tombamento nacional realizado pelo IPHAN, os órgãos estaduais e municipais competentes também podem realizar o tombamento de patrimônios nos seus respectivos âmbitos administrativos.

Em escala mundial, a UNESCO é a entidade que promove a proteção dos patrimônios da humanidade (World Heritage). Em 1972, esta instituição organizou a "Convenção para a proteção do Patrimônio Mundial, Cultural e Natural". A Convenção funciona como um tratado que busca identificar, proteger e preservar o patrimônio cultural e natural ao redor do mundo, considerando seu valor excepcional para a humanidade. Este tratado ocorreu devido à necessidade de proteger elementos de valor cultural $\mathrm{e}$ áreas naturais (Zanirato, 2008), e nele foram definidos os patrimônios culturais e naturais considerados patrimônios mundiais da humanidade, conforme a Tabela III.

Tabela III. Definição de patrimônio cultural e natural segundo UNESCO.

\begin{tabular}{|c|c|}
\hline Patrimônios Culturais & $\begin{array}{l}\text { - Monumentos: Obras arquitetônicas, de escultura ou de } \\
\text { pintura monumentais, elementos de estruturas de } \\
\text { caráter arqueológico, inscrições, grutas e grupos de } \\
\text { elementos com valor universal excepcional do ponto de } \\
\text { vista da história, da arte ou da ciência; } \\
\text { - Os conjuntos: Grupos de construções isoladas ou } \\
\text { reunidos que, em virtude da sua arquitetura, unidade ou } \\
\text { integração na paisagem têm valor universal excepcional } \\
\text { do ponto de vista da história, da arte ou da ciência; } \\
\text { - Os locais de interesse: Obras do homem, ou obras } \\
\text { conjugadas do homem e da natureza, e as zonas, } \\
\text { incluindo os locais de interesse arqueológico, com um } \\
\text { valor universal excepcional do ponto de vista histórico, } \\
\text { estético, etnológico ou antropológico. }\end{array}$ \\
\hline Patrimônios Naturais & $\begin{array}{l}\text { - Monumentos naturais constituídos por formações físicas } \\
\text { e biológicas ou por grupos de tais formações com valor } \\
\text { universal excepcional do ponto de vista estético ou } \\
\text { científico; } \\
\text { - As formações geológicas e fisiográficas e as zonas } \\
\text { estritamente delimitadas que constituem habitat de } \\
\text { espécies animais e vegetais ameaçadas, com valor } \\
\text { universal excepcional do ponto de vista da ciência ou da } \\
\text { conservação; } \\
\text { - Os locais de interesse natural ou zonas naturais } \\
\text { estritamente delimitadas, com valor universal } \\
\text { excepcional do ponto de vista a ciência, conservação ou } \\
\text { beleza natural. }\end{array}$ \\
\hline
\end{tabular}

Fonte: Convenção para a proteção do patrimônio mundial, cultural e natural - Art. $1^{\circ}$ e $2^{\circ}$ UNESCO 


\subsection{Monumentos Naturais no Brasil}

Segundo o painel do Cadastro Nacional de Unidades de Conservação, acessado em 19 de julho de 2019, existe um total de 2.309 unidades de conservação da natureza nas três esferas administrativas do Brasil, sendo 742 de proteção integral e 1.567 do grupo de uso sustentável. Os monumentos naturais fazem parte do grupo de proteção integral e correspondem a aprox. 2,5\% do número de unidades de conservação. Cabe destacar que, apesar da pequena proporção em relação ao total de unidades de conservação, os dois Monumentos Naturais criados recentemente em ambiente marinho - o Monumento Natural das Ilhas de Trindade, Martim Vaz e do Monte Columbia e o Monumento Natural do Arquipélago de São Pedro de São Paulo - têm uma área expressiva que, compõe cerca de $98,7 \%$ do total da área coberta por Monumentos Naturais, tanto no continente quanto em área marinha.

Existem apenas 60 Monumentos Naturais no Brasil cadastrados no CNUC (Tabela IV). Contudo, desde a sua criação, esta categoria vem crescendo ao longo dos anos, como mostra a figura 1 , e teve seu maior pico no ano de 2010 , quando foram criadas quinze unidades de conservação na categoria Monumento Natural.

Tabela IV. Unidades de Conservação da categoria de Monumento Natural. As categorias correspondem a: Geo - Geodiversidade, Bio - Biodiversidade, Cult - Aspecto Cultural.

\begin{tabular}{|c|c|c|c|c|}
\hline Monumento Natural & Categorias & Atributo 1 & Atributo 2 & Atributo 3 \\
\hline $\begin{array}{l}\text { Monumento Natural das Ilhas de } \\
\text { Trindade, Martim Vaz e do Monte } \\
\text { Columbia, BA }\end{array}$ & Geo e Bio & Ilhas Oceânicas & $\begin{array}{l}\text { Espécies } \\
\text { endêmicas }\end{array}$ & Espécies raras \\
\hline $\begin{array}{l}\text { Monumento Natural do } \\
\text { Arquipélago de São Pedro e São } \\
\text { Paulo, PB }\end{array}$ & Geo e Bio & Ilhas Oceânicas & $\begin{array}{l}\text { Espécies } \\
\text { endêmicas }\end{array}$ & Espécies raras \\
\hline $\begin{array}{l}\text { Monumento Natural do Rio São } \\
\text { Francisco, AL/BA/SE }\end{array}$ & Geo & Cânions & Rios & \\
\hline $\begin{array}{l}\text { Monumento Natural dos Pontões } \\
\text { Capixabas, ES }\end{array}$ & Geo & Inselberg & & \\
\hline $\begin{array}{l}\text { Monumento Natural das Ilhas } \\
\text { Cagarras, RJ }\end{array}$ & Geo e Bio & Inselberg & $\begin{array}{l}\text { Refúgio de } \\
\text { espécies }\end{array}$ & Ninhal \\
\hline $\begin{array}{l}\text { Monumento Natural Distrital do } \\
\text { Conjunto Espeleológico do Morro } \\
\text { da Pedreira, DF }\end{array}$ & Geo & Cavidade natural & $\begin{array}{l}\text { Resquícios } \\
\text { paleontológicos }\end{array}$ & $\begin{array}{l}\text { Resquícios } \\
\text { arqueológicos }\end{array}$ \\
\hline $\begin{array}{l}\text { Monumento Natural Estadual da } \\
\text { Gruta do Lago Azul, MS }\end{array}$ & Geo & Cavidade natural & $\begin{array}{l}\text { Resquícios } \\
\text { paleontológicos }\end{array}$ & $\begin{array}{l}\text { Resquícios } \\
\text { arqueológicos }\end{array}$ \\
\hline $\begin{array}{l}\text { Monumento Natural Estadual do } \\
\text { Rio Formoso, MS }\end{array}$ & Geo & Cachoeiras & & \\
\hline $\begin{array}{l}\text { Monumento Natural Estadual } \\
\text { Morro de Santo Antônio, MT }\end{array}$ & Cult & Fato histórico & & \\
\hline $\begin{array}{l}\text { Monumento Natural Estadual das } \\
\text { Árvores Fossilizadas, TO }\end{array}$ & Geo & $\begin{array}{l}\text { Resquícios } \\
\text { paleontológicos }\end{array}$ & & \\
\hline $\begin{array}{l}\text { Monumento Natural Estadual } \\
\text { Cachoeira do Ferro Doido, BA }\end{array}$ & Geo & Cachoeira & & \\
\hline $\begin{array}{l}\text { Munumento Natural Estadual dos } \\
\text { Canions do Subaé, BA }\end{array}$ & Geo & Cânions & Cachoeiras & Rios \\
\hline $\begin{array}{l}\text { Monumento Natural Estadual das } \\
\text { Falésias de Beberibe, CE }\end{array}$ & Geo & Falésias & Dunas & \\
\hline $\begin{array}{l}\text { Monumento Natural Estadual } \\
\text { Monólitos de Quixadá, CE }\end{array}$ & Geo & Inselberg & & \\
\hline
\end{tabular}




\begin{tabular}{|c|c|c|c|c|}
\hline $\begin{array}{l}\text { Monumento Natural Estadual } \\
\text { Sítio Cana Brava, CE }\end{array}$ & Geo & $\begin{array}{l}\text { Resquícios } \\
\text { paleontológicos }\end{array}$ & & \\
\hline $\begin{array}{l}\text { Monumento Natural Estadual } \\
\text { Sítio Riacho do Meio, CE }\end{array}$ & Geo & $\begin{array}{l}\text { Resquícios } \\
\text { paleontológicos }\end{array}$ & & \\
\hline $\begin{array}{l}\text { Monumento Natural Estadual } \\
\text { Vale dos Dinossauros, PB }\end{array}$ & Geo & $\begin{array}{l}\text { Resquícios } \\
\text { paleontológicos }\end{array}$ & & \\
\hline $\begin{array}{l}\text { Monumento Natural Estadual } \\
\text { Pedra do Cachorro, PE }\end{array}$ & Geo e Bio & Maciço & $\begin{array}{l}\text { Espécies } \\
\text { endêmicas }\end{array}$ & \\
\hline $\begin{array}{l}\text { Monumento Natural Estadual } \\
\text { Grota do Angico, SE }\end{array}$ & Cult & Fato histórico & & \\
\hline $\begin{array}{l}\text { Monumento Natural Estadual o } \\
\text { Frade e a Freira, ES }\end{array}$ & Geo e Cult & Inselberg & Lenda & \\
\hline $\begin{array}{l}\text { Monumento Natural Estadual } \\
\text { Serra das Torres, ES }\end{array}$ & Geo & Serra & & \\
\hline $\begin{array}{l}\text { Monumento Natural Estadual de } \\
\text { Itatiaia, MG }\end{array}$ & Geo & Serra & & \\
\hline $\begin{array}{l}\text { Monumento Natural Estadual de } \\
\text { Santo Antônio, MG }\end{array}$ & Geo & Cavidade natural & & \\
\hline $\begin{array}{l}\text { Monumento Natural Estadual } \\
\text { Peter Lund, MG }\end{array}$ & Geo & Cavidade natural & \begin{tabular}{|l|} 
Resquícios \\
paleontológicos
\end{tabular} & \begin{tabular}{|l|} 
Resquícios \\
arqueológicos
\end{tabular} \\
\hline $\begin{array}{l}\text { Monumento Natural Estadual } \\
\text { Experiência da Jaguara, MG }\end{array}$ & Geo & Maciço & $\begin{array}{l}\text { Cavidade } \\
\text { natural }\end{array}$ & $\begin{array}{l}\text { Resquícios } \\
\text { paleontológico } \\
\text { s }\end{array}$ \\
\hline $\begin{array}{l}\text { Monumento Natural Estadual } \\
\text { Gruta Rei do Mato, MG }\end{array}$ & Geo & Cavidade natural & $\begin{array}{l}\text { Resquícios } \\
\text { paleontológicos }\end{array}$ & $\begin{array}{l}\text { Resquícios } \\
\text { arqueológicos }\end{array}$ \\
\hline $\begin{array}{l}\text { Monumento natural estadual lapa } \\
\text { nova de vazante, mg }\end{array}$ & Geo & Cavidade natural & $\begin{array}{l}\text { Resquícios } \\
\text { paleontológicos }\end{array}$ & $\begin{array}{l}\text { Resquícios } \\
\text { arqueológicos }\end{array}$ \\
\hline $\begin{array}{l}\text { Monumento Natural Estadual } \\
\text { Lapa Vermelha, MG }\end{array}$ & Geo & Cavidade natural & $\begin{array}{l}\text { Resquícios } \\
\text { paleontológicos }\end{array}$ & $\begin{array}{l}\text { Resquícios } \\
\text { arqueológicos }\end{array}$ \\
\hline $\begin{array}{l}\text { Monumento Natural Estadual } \\
\text { Pico do Ibituruba, mg }\end{array}$ & Geo e Bio & Maciço & rios & \\
\hline $\begin{array}{l}\text { Monumento Natural Estadual } \\
\text { Serra da Moeda, MG }\end{array}$ & Geo e Bio & Serra & \begin{tabular}{|l|} 
espécies \\
endêmicas
\end{tabular} & \\
\hline $\begin{array}{l}\text { Monumento Natural Estadual } \\
\text { Serra do Gambá, MG }\end{array}$ & Geo & Serra & & \\
\hline $\begin{array}{l}\text { Monumento Natural Estadual } \\
\text { Vargem da Pedra, MG }\end{array}$ & Geo & Cavidade natural & & \\
\hline $\begin{array}{l}\text { Monumento Natural Estadual } \\
\text { Várzea da Lapa, MG }\end{array}$ & Geo & Cavidade natural & \begin{tabular}{|l|} 
resquícios \\
arqueológicos
\end{tabular} & \\
\hline $\begin{array}{l}\text { Monumento Natural Estadual } \\
\text { Várzea do Lageado e Serra do } \\
\text { Raio, MG }\end{array}$ & Geo e Bio & $\begin{array}{l}\text { espêcies } \\
\text { endêmicas }\end{array}$ & serra & cachoeiras \\
\hline $\begin{array}{l}\text { Monumento Natural Estadual da } \\
\text { Serra da Beleza, RJ }\end{array}$ & Geo & Serra & & \\
\hline $\begin{array}{l}\text { Monumento Natural Estadual da } \\
\text { Pedra do Baú, SP }\end{array}$ & Geo & Maciço & & \\
\hline $\begin{array}{l}\text { Monumento Natural Estadual da } \\
\text { Pedra Grande, SP }\end{array}$ & Geo & Maciço & & \\
\hline $\begin{array}{l}\text { Monumento Natural Estadual } \\
\text { Gruta da Lancinha, Pr }\end{array}$ & Geo & Cavidade natural & \begin{tabular}{|l|} 
Resquícios \\
paleontológicos
\end{tabular} & $\begin{array}{l}\text { Resquícios } \\
\text { arqueológicos }\end{array}$ \\
\hline $\begin{array}{l}\text { Monumento Natural Municipal } \\
\text { das Lagoas, MS }\end{array}$ & Bio & Lagoa & & \\
\hline $\begin{array}{l}\text { Monumento Natural Municipal } \\
\text { Serra do Bom Jardim, MS }\end{array}$ & Geo & Serra & & \\
\hline $\begin{array}{l}\text { Monumento Natural Municipal } \\
\text { Canyons e Corredeiras do Rio } \\
\text { Sono, TO }\end{array}$ & Geo & Serra & & \\
\hline $\begin{array}{l}\text { Monumento Natural Municipal } \\
\text { Morro Chico Mendes, RO }\end{array}$ & Geo & Maciço & & \\
\hline
\end{tabular}




\begin{tabular}{|c|c|c|c|c|}
\hline $\begin{array}{l}\text { Monumento Natural Municipal } \\
\text { Península da Siribinha. BA }\end{array}$ & Geo & Dunas & Rios & \\
\hline $\begin{array}{l}\text { Monumento Natural Municipal do } \\
\text { Itabira, ES }\end{array}$ & Geo & Maciço & & \\
\hline $\begin{array}{l}\text { Monumento Natural Municipal } \\
\text { Falésia de Marataízes, ES }\end{array}$ & Geo & Falésias & & \\
\hline $\begin{array}{l}\text { Monumento Natural Municipal } \\
\text { Nossa Senhora da Lapa, MG }\end{array}$ & Cult & Fato histórico & & \\
\hline $\begin{array}{l}\text { Monumento Natural Municipal } \\
\text { Serra da Ferrugem, MG }\end{array}$ & Geo e Cult & Maciço & Lenda & \\
\hline $\begin{array}{l}\text { Monumento Natural Municipal da } \\
\text { Floresta, RJ }\end{array}$ & Geo & Rios & Maciços & \\
\hline $\begin{array}{l}\text { Monumento Natural Municipal da } \\
\text { Pedra de Itaocaia, RJ }\end{array}$ & Geo & Maciço & & \\
\hline $\begin{array}{l}\text { Monumento Natural Municipal da } \\
\text { Pedra do Colégio, RJ }\end{array}$ & Geo & Inselberg & & \\
\hline $\begin{array}{l}\text { Monumento Natural Municipal da } \\
\text { Pedra do Elefante, rj }\end{array}$ & Geo & Maciço & $\begin{array}{l}\text { Espécies } \\
\text { endêmicas }\end{array}$ & Espécies raras \\
\hline $\begin{array}{l}\text { Monumento Natural Municipal da } \\
\text { Pedra do Inoã, RJ }\end{array}$ & Geo & Inselberg & & \\
\hline $\begin{array}{l}\text { Monumento Natural Municipal da } \\
\text { Serra da Bolívia, RJ }\end{array}$ & Geo & Cachoeiras & Cânions & Rios \\
\hline $\begin{array}{l}\text { Monumento Natural Municipal do } \\
\text { Encontro dos Três Rios, RJ }\end{array}$ & Geo & Serra & Rios & \\
\hline $\begin{array}{l}\text { Monumento Natural Municipal } \\
\text { dos Morros do Pão de Açúcar e } \\
\text { Urca, RJ }\end{array}$ & Geo e Cult & Inselberg & & \\
\hline $\begin{array}{l}\text { Monumento Natural Municipal } \\
\text { São Simão, RJ }\end{array}$ & Geo & Maciço & & \\
\hline $\begin{array}{l}\text { Monumento Natural Municipal do } \\
\text { Pico do Itaguaré, SP }\end{array}$ & Geo e Bio & Serra & \begin{tabular}{|l} 
espécies \\
endêmicas
\end{tabular} & espécies raras \\
\hline $\begin{array}{l}\text { Monumento Natural Municipal } \\
\text { Capão da Amizade, RS }\end{array}$ & Cult & Fato histórico & & \\
\hline $\begin{array}{l}\text { Monumento Natural Municipal da } \\
\text { Galheta, SC }\end{array}$ & Geo & Inselberg & & \\
\hline $\begin{array}{l}\text { Monumento Natural Municipal da } \\
\text { Lagoa do Peri, SC }\end{array}$ & Geo & Lagoa & & \\
\hline
\end{tabular}

Fonte: Cadastro Nacional de Unidades de Conservação e atributos obtidos nos documentos de criação das unidades de conservação, no CNUC ou páginas associadas.

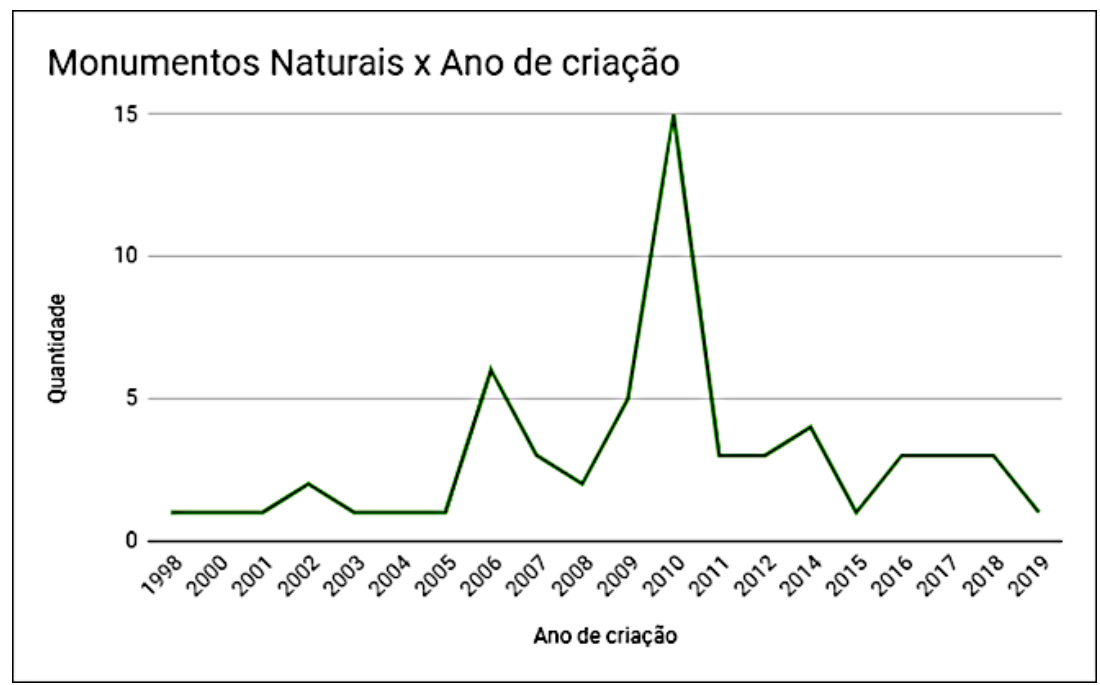

Figura 1: Histórico da criação dos Monumentos Naturais no Brasil.

Fonte: Cadastro Nacional de Unidades de Conservação (CNUC). 
O mapa na figura 2 mostra a localização dos Monumentos Naturais federais, estaduais e municipais brasileiros. A partir da leitura deste mapa, podemos identificar, facilmente, que a maior parte das unidades de conservação desta categoria encontrase na região sudeste, estando em menor número nas regiões sul, norte e centro-oeste.

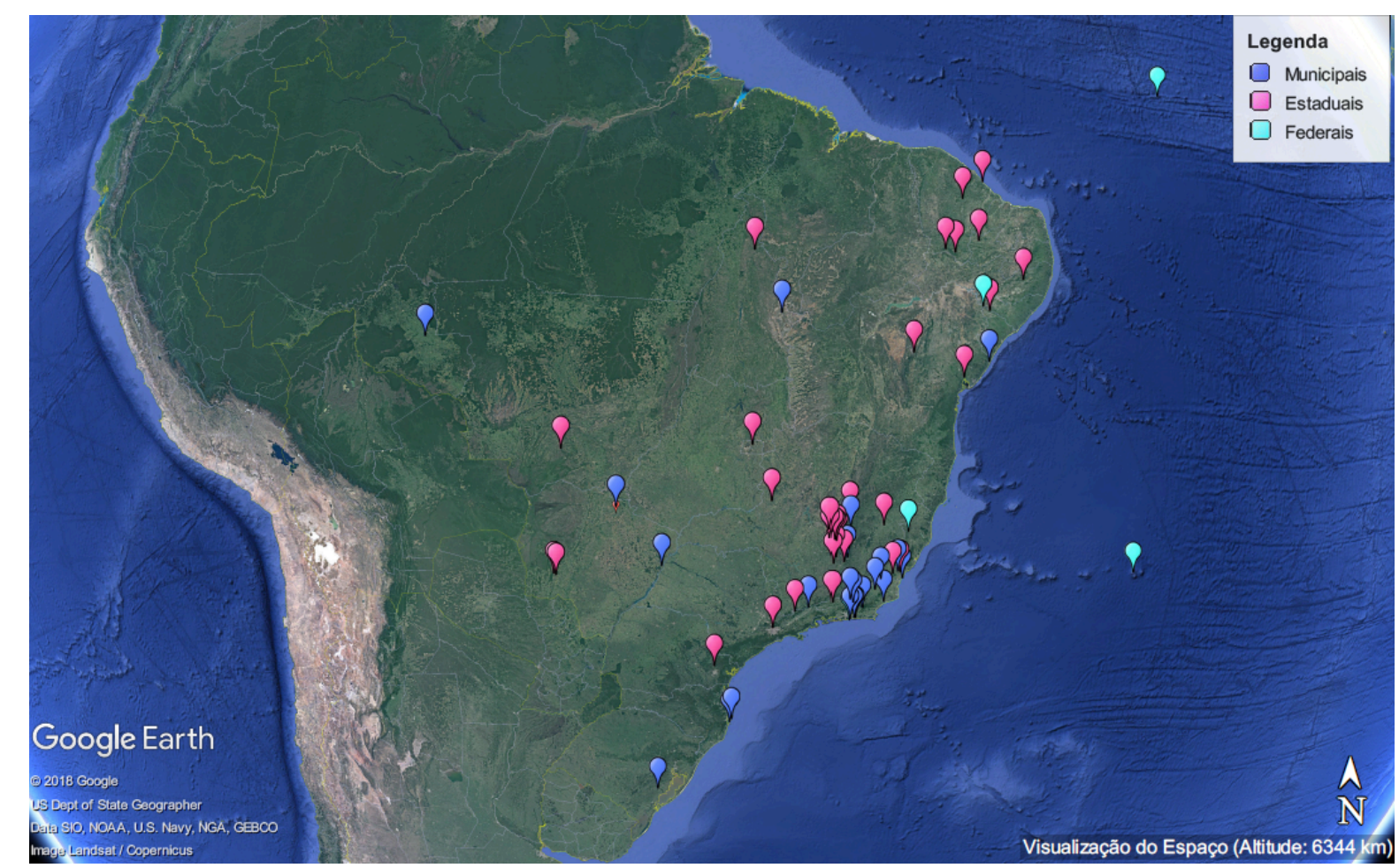

Figura 2: Localização das áreas protegidas da categoria de Monumento Natural no Brasil.

Fonte: Cadastro Nacional de Unidades de Conservação (CNUC). Acesso em: 30 de julho de 2019. Imagem obtida através do software Google EarthTM, 2013.

$\mathrm{Na}$ figura 3, confirma-se que a maior parte das unidades desta categoria está localizada na região sudeste. Eles estão concentrados, principalmente, nos estados de Minas Gerais, Rio de Janeiro e Espírito Santo.

Apesar de existirem apenas dois Monumentos Naturais na região norte, a área ocupada por esta categoria é extensa, pois nesta região está localizado o maior Monumento Natural brasileiro, com, aproximadamente, 32.000 ha. Assim, a área ocupada por esta categoria de unidade de conservação está bem distribuída entre as regiões norte, nordeste e sudeste, que correspondem respectivamente a $26 \%, 36 \%$ e $38 \%$ da área total. Porém, as regiões sul e centro-oeste correspondem a menos de $1 \%$ da área total.

O somatório do tamanho da área ocupada pelos Monumentos Naturais federais, estaduais e municipais corresponde a um total de, aproximadamente, 11.643.252,5 ha, que varia entre 1 e 676.796,4 ha. Os Monumentos Naturais marinhos criados em 2018 - Monumento Natural da llha de Trindade, Martim Vaz e Monte Columbia e Monumento Natural do Arquipélago de São Pedro e São Paulo são constituídos por $98,6 \%$ da totalidade da área dos Monumentos Naturais no país. Excluindo estas duas 
exceções desproporcionais, nos $1,4 \%$ da área de Monumentos Naturais remanescente estão as demais 58 UCs desta categoria. Entre estas, a maior, continental é o Monumento Natural Estadual das Árvores Fossilizadas, no Estado do Tocantins, com 32.067,10 ha.

\section{Monumentos Naturais por região do Brasil}

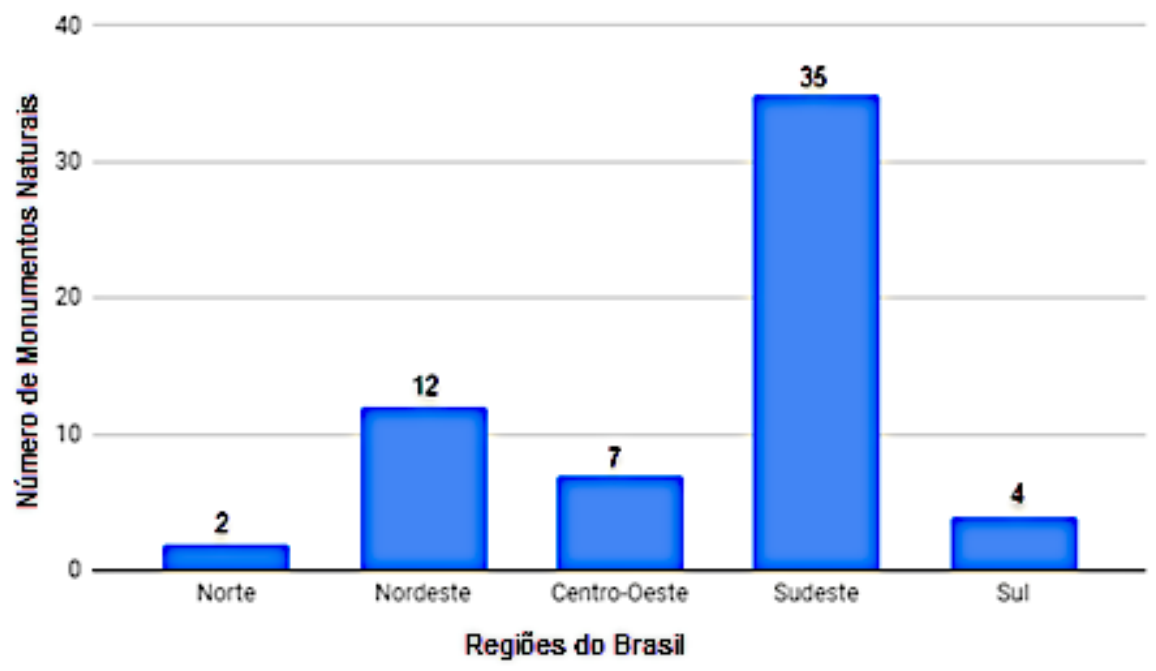

Figura 3: Monumentos Naturais por região geográfica do Brasil. No gráfico, são apresentados dos valores absolutos.

Fonte: Cadastro Nacional de Unidades de Conservação (CNUC).

A média entre os Monumentos Naturais, excluindo os de grande área marinha, é de $2.533,38$ ha e a mediana de 255,51 ha. A partir destes dados, pode-se concluir que, apesar da média ser alta, a medida central é consideravelmente menor, o que indica que existem poucos Monumentos Naturais com áreas muito grandes, $e^{1 / 4}$ deles possui o tamanho de sua área menor que 70 ha, e metade atinge no máximo 261 ha.

O território brasileiro é composto por sete grandes biomas terrestres e o ambiente marinho. Os biomas terrestres são: Amazônia, Pantanal, Cerrado, Caatinga, Pampa e Mata Atlântica. O Cerrado e a Mata Atlântica foram os biomas mais contemplados com a categoria de Monumentos Naturais, com $42 \%$ e $39 \%$, respectivamente. A caatinga representa apenas $16 \%$ e o bioma marinho possui apenas seis Monumentos Naturais e representa $10 \%$ do total de unidades, mas $98 \%$ da área total da categoria, como já foi apresentado. Nos biomas do pantanal, pampa não foram registrados nenhum Monumento Natural. Na Amazônia o único é o Monumento Natural Municipal do Morro do Chico Mendes, um maciço na área urbana de Ouro Preto do Oeste, Estado de Rondônia, utilizado em práticas de esportes de aventura.

Observa-se, na Figura 4, que a grande maioria dos Monumentos Naturais apresenta entre os seus principais atributos, aspectos relacionados à geodiversidade. De acordo com o Serviço Geológico do Brasil (CPRM) a geodiversidade é definida como:

O estudo da natureza abiótica (meio físico) constituída por uma variedade de ambientes, composição, fenômenos e processos 
geológicos que dão origem às paisagens, rochas, minerais, águas, fósseis, solos, clima e outros depósitos superficiais que propiciam o desenvolvimento de vida na Terra, tendo como valores intrínsecos a cultura, o estético, o econômico, o científico, o educativo e o turístico. (Silva, 2008, p.12)

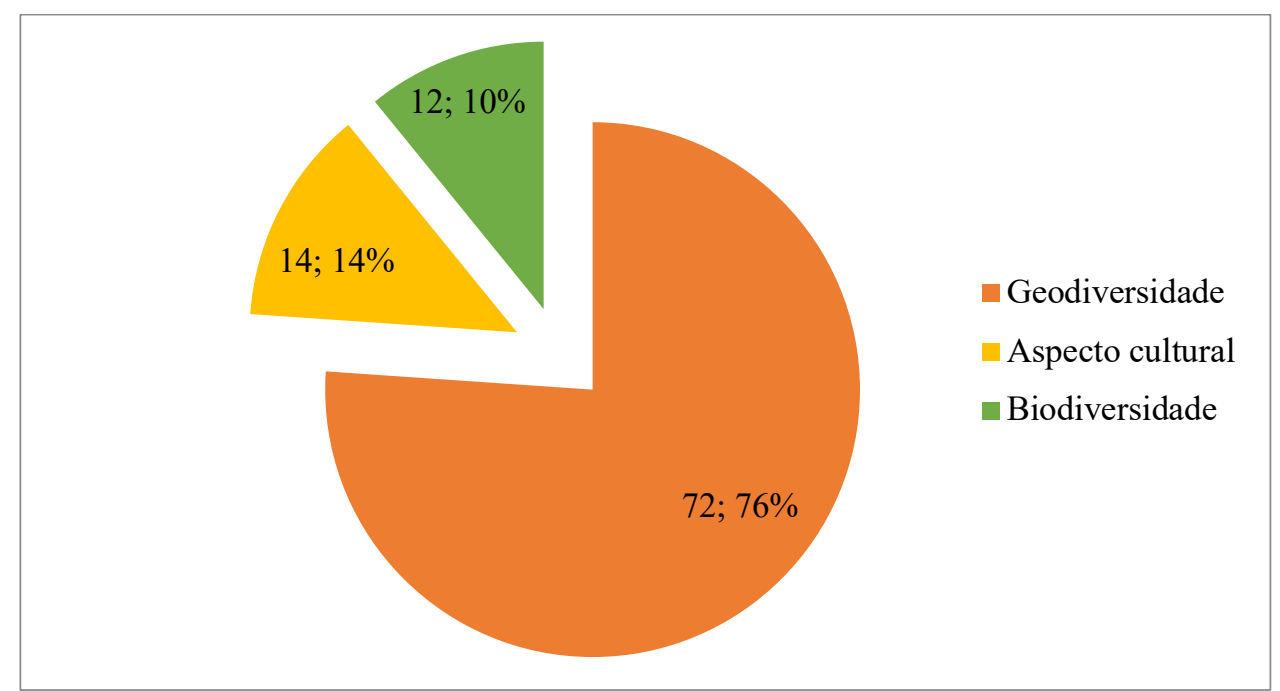

Figura 4: Distribuição de atributos principais por categoria nos Monumentos Naturais. Os valores absolutos, são apresentados seguidos das suas respectivas porcentagens.

Fonte: Autoria própria

Desta forma, entende-se que os aspectos associados à geodiversidade estão diretamente relacionados com a beleza cênica local, pois esta categoria de atributos é constituída pelos principais elementos que dão origem à formação da paisagem natural. Isto justifica o fato de $76 \%$ dos atributos principais dos Monumentos Naturais estarem relacionados à geodiversidade, tendo em vista a definição do conceito desta categoria de unidade de conservação que busca preservar sítios naturais raros, singulares ou de grande beleza cênica. Cada Monumento Natural apresenta uma ou duas categorias de atributos principais. Devido ao fato de alguns monumentos naturais apresentarem mais de uma categoria, o somatório dos atributos é maior que o número de monumentos naturais.

A categoria de atributos principais de biodiversidade foi encontrada em apenas cinco Monumentos Naturais e apresentou-se sempre associada a elementos de geodiversidade. Já a categoria de atributos principais de aspecto cultural apareceu em seis Monumentos Naturais. Mesmo naquelas onde a principal justificativa para criação da área protegida foi um fato histórico, como por exemplo, o Monumento Natural da Grota do Angico, onde foram mortos Lampião, Maria Bonita e outros cangaceiros, a toponímia não deixa dúvida da influência da geomorfologia.

A categoria de geodiversidade apresentou como atributos principais as seguintes características geológicas: maciços, inselbergs, serras, resquícios paleontológicos, resquícios arqueológicos, cavidades naturais, rios, cânions, cachoeiras, falésias e dunas. A categoria de biodiversidade apresentou como atributos principais as seguintes características: refúgio de espécies, espécies raras ou espécies endêmicas. 
E a categoria de aspectos culturais apresentou como atributos principais aspectos relacionados a fatos históricos ou lendas.

Verifica-se na Figura 5 que a maioria dos Monumentos Naturais que apresentaram a geodiversidade como categoria de atributo principal, revelaram como características a constituição de feições marcantes do relevo (inselbergs, maciços e serras), cavidades naturais, resquícios paleontológicos e resquícios arqueológicos, sendo que estes três últimos aparecem, por vezes, relacionadas entre si.

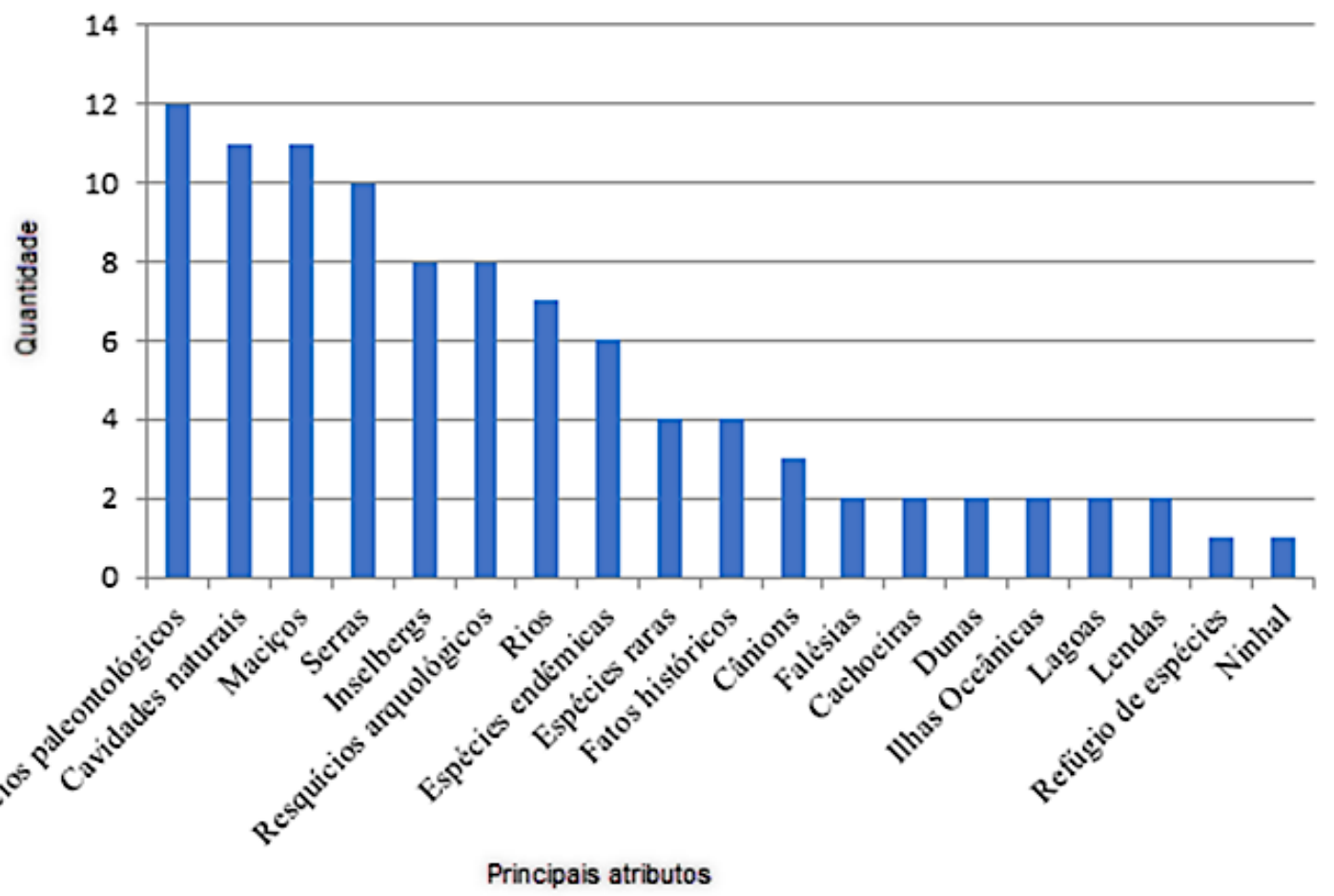

Figura 5: Número de vezes em que aparecem os atributos principais nos Monumentos Naturais Brasileiros.

Fonte: autoria própria.

\subsection{Monumentos Naturais Federais}

Existem três Monumentos Naturais federais brasileiros e são administrados pelo Instituto Chico Mendes de Conservação da Biodiversidade (ICMBIO), o Monumento Natural das Ilhas Cagarras, o Monumento Natural dos Pontões Capixabas e o Monumento Natural do Rio São Francisco. Eles abrangem os estados do Rio de Janeiro, Espírito Santo, Bahia, Alagoas e Sergipe, respectivamente, sendo que os últimos três estados fazem parte de um único Monumento. A soma das áreas destes Monumentos representa aproximadamente 44.300 ha, o que corresponde a $34 \%$ do total. Exceto o Monumento Natural das Ilhas Cagarras, os outros dois Monumentos Naturais estão entre os cinco com os maiores territórios desta categoria e apresentam áreas muito acima da média encontrada. 


\subsection{Monumentos Naturais Estaduais}

Os Monumentos Naturais estaduais encontram-se em maior número dentre as esferas administrativas, representado, aproximadamente, $70 \%$ do total desta categoria de unidade de conservação no país, como mostra o gráfico abaixo.

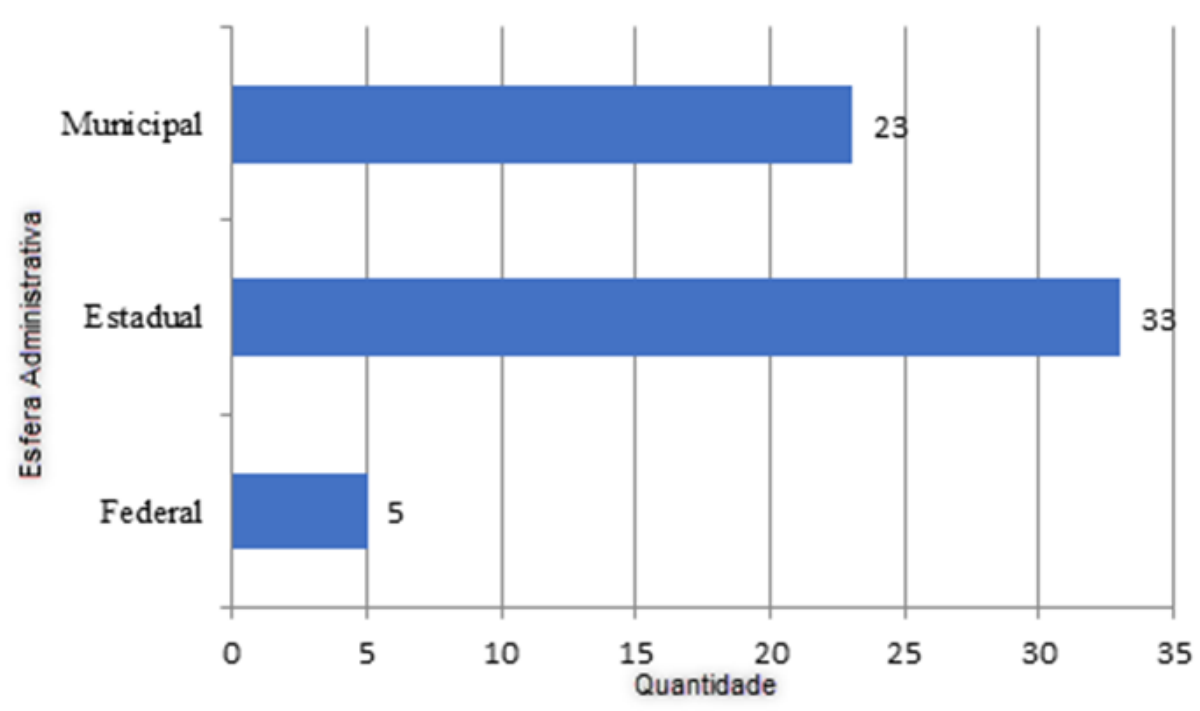

Figura 6: Monumentos naturais por esfera administrativa.

Fonte: Cadastro Nacional de Unidades de Conservação (CNUC).

O estado com o maior número de Monumentos Naturais estaduais é o de Minas Gerais. Este fato se deve pela criação do Sistema de Áreas Protegidas do Vetor Norte Metropolitano de Belo Horizonte, que resultou na criação de diversas unidades de conservação na região, dentre elas, sete Monumentos Naturais estaduais foram criados em Minas Gerais entre os anos de 2010 e 2011.

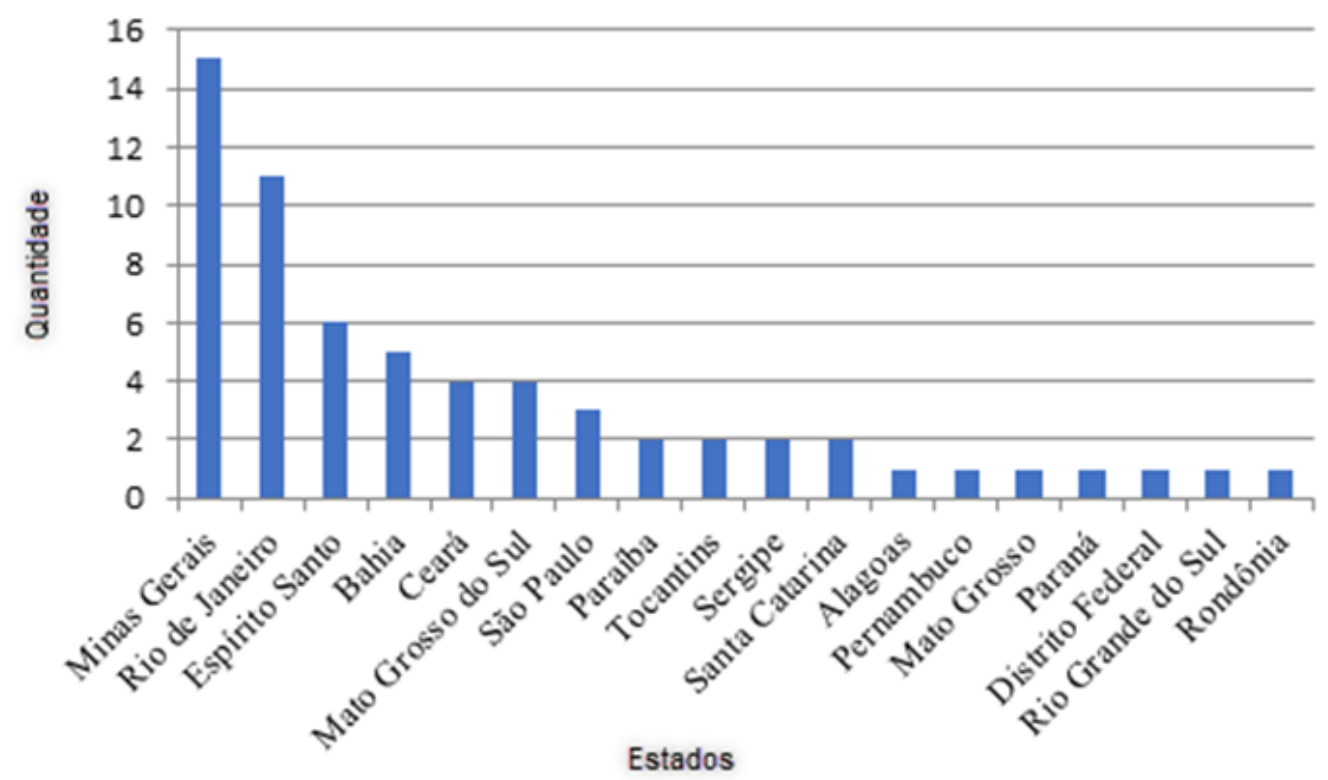

Figura 7: Monumentos Naturais estaduais por estados brasileiros.

Fonte: Cadastro Nacional de Unidades de Conservação (CNUC). 


\subsection{Monumentos Naturais Municipais}

Existem nove Monumentos Naturais municipais e eles estão distribuídos pelos seguintes estados: Minas Gerais, Tocantins, Rio de Janeiro, São Paulo, Espírito Santo e Rio Grande do Sul. O estado com o maior número de Monumentos Naturais municipais é o do Rio de Janeiro com $45 \%$ do total, como se pode observar na Figura 8.

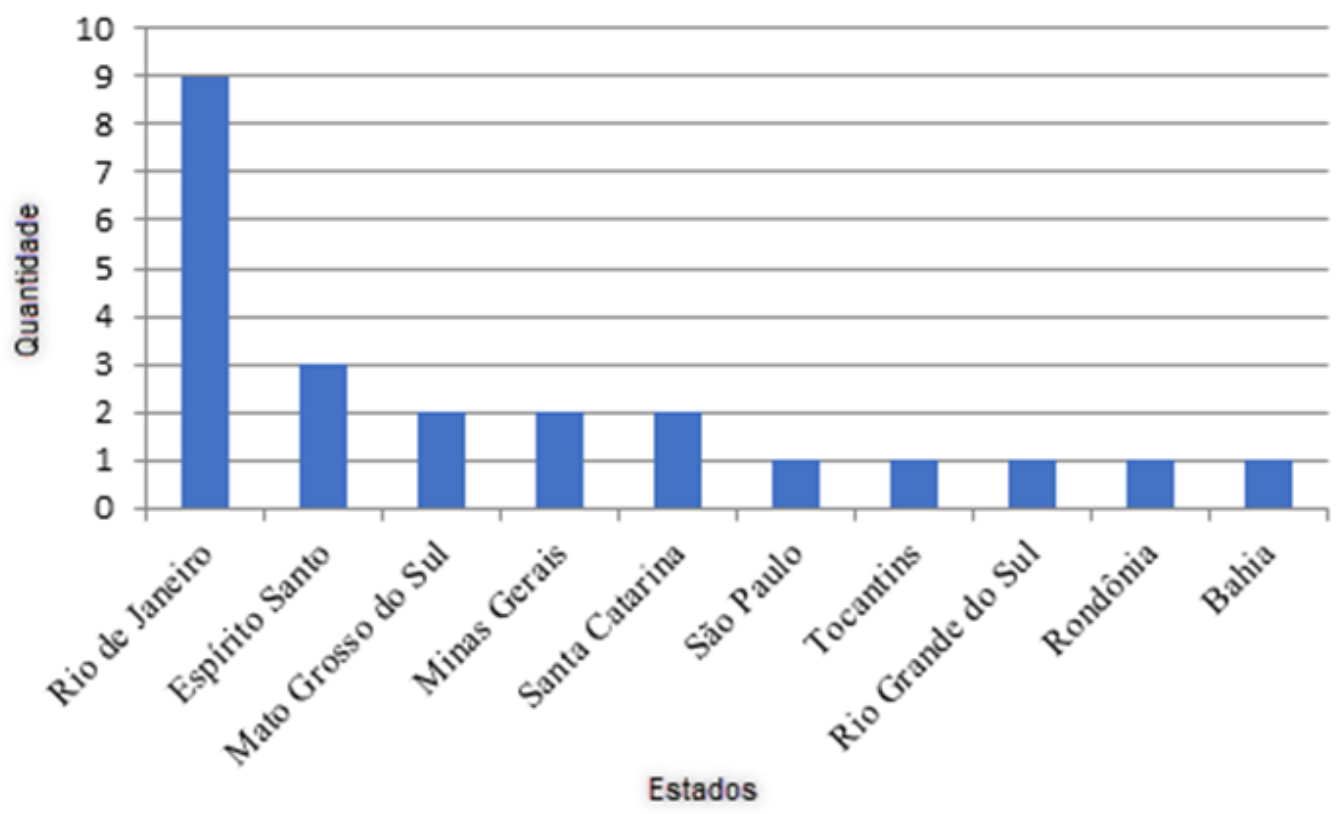

Figura 8: Monumentos Naturais municipais por estado.

Fonte: Cadastro Nacional de Unidades de Conservação (CNUC).

Esta evidência pode estar associada ao relevo acidentado característico do estado do Rio de Janeiro que possui significativa vocação para a apresentação de variados afloramentos rochosos, originando a geodiversidade típica da região. A importância e o destaque para este relevo característico é corroborado, por exemplo, pela inclusão da cidade do Rio de Janeiro na Lista de Patrimônio Mundial pela UNESCO. A capital do estado do Rio de Janeiro entrou para a Lista na categoria de paisagem cultural pelo seu cenário urbano excepcional, nomeada, em 2012, como "Rio de Janeiro, paisagens cariocas entre a montanha e o mar".

\section{Discussão}

No Sistema brasileiro de áreas protegidas - SNUC - observa-se que a maioria das unidades de conservação estão inseridas no grupo de uso sustentável. Este fato se deve, principalmente, pelo grande número de Reservas Particulares do Patrimônio Natural que extrapola a soma das unidades de conservação do grupo de proteção integral. Dentro do grupo de proteção integral, a categoria de Parques é a mais popular, estando em maior número que as demais categorias do grupo. Parque também foi a primeira categoria de área protegida adotada no país. Por isso, os parques são as UCs mais antigas e abrigam diversas feições geográficas que podem 
ser consideradas monumentos naturais, como a montanha do Corcovado, no Parque Nacional da Tijuca e as Cataratas do Iguaçu, no Parque Nacional do Iguaçu. Isso para citar os dois parques mais visitados do Brasil.

A partir das definições de patrimônio cultural e natural apresentadas pela UNESCO, pode-se afirmar que todos os elementos considerados patrimônio cultural possuem algum tipo de relação com a paisagem ou natureza vinculados a aspectos antropológicos. Já aqueles considerados patrimônio natural estão estritamente ligados a conservação da paisagem natural e/ou da biodiversidade local. Desta forma, podemos perceber que os monumentos naturais possuem relação direta com a idéia de herança assim como o patrimônio, esteja este vinculado a aspectos culturais ou naturais.

Como demonstrado, a categoria de área protegida, no Brasil, unidade de conservação, Monumento Natural é em sua grande maioria ligada a atributos de geodiversidade. A definição de Monumento Natural remete necessariamente à de patrimônio (heritage) e este, por sua vez a aspectos culturais de valorização do território. Estes aspectos culturais estão mais frequentemente associados a feições geográficas de relevo e outros de geomorfologia e paleontologia. A influência cultural do relevo e de suas características está gravada na toponímia e no imaginário cultural.

As unidades de conservação da categoria Monumento Natural no Brasil são tipicamente pequenas, e incluem morros, cavernas, montanhas, áreas que podem ser delimitadas com tamanho relativamente pequeno, entre um e 250 ha. Áreas de monumentos maiores são encontradas na Amazônia Legal, estado do Tocantins, no Canyon do Rio São Francisco e nas áreas marinhas circundantes dos Rochedos São Pedro e São Paulo e nas Ilhas de Trindade, Matim Vaz e do Monte Columbia. Especialmente estas duas últimas, são responsáveis por grande parte da área protegida em ambiente marinho no Brasil.

Conforme demonstrado, as unidades de conservação da categoria Monumento Natural no Brasil são constituídos, em sua maioria por feições notáveis da geodiversidade. Esta característica deveria ser reconhecida na definição da categoria de forma a orientar as práticas de manejo voltadas à visitação e conservação da geodiversidade.

\section{Agradecimentos}

Agradecemos o apoio do Programa de Pós-Graduação em Ecoturismo e Conservação - PPGEC da Universidade Federal do Estado do Rio de Janeiro - UNIRIO e ao Centro de Estudos de Geografia e Ordenamento do Território - CEGOT - Universidade de Coimbra.

\section{Disponibilidade dos Dados científicos}

Os dados deste estudo foram obtidos junto à base de dados Cadastro Nacional de Unidades de Conservação do Brasil, mantido pelo Instituto de Conservação da Biodiversidade - ICMBio (Ministério do Meio Ambiente, 2019). Consultado pela última 
vez em 12 de julho de 2019 em http://www.mma.gov.br/areas-protegidas/cadastronacional-de-ucs/consulta-gerar-relatorio-de-uc

\section{Bibliografia}

Bensusan, N. (2006). Conservação da Biodiversidade em Áreas Protegidas. Rio de Janeiro: Editora FGV.

Brasil (1937). Organiza a proteção do patrimônio histórico e artístico nacional. Decreto-lei n. 25, de 30 de novembro de 1937. Disponível em 12/07/2019 em: http://www.planalto.gov.br/ccivil 03/decreto-lei/del0025.htm

Brasil (1988). Constituição da República Federativa do Brasil de 1988. Disponível em $12 / 07 / 2019$ em: http://www.planalto.gov.br/ccivil 03/constituicao/constituicaocompilado.htm

Brasil (2002). Regulamenta artigos da Lei n. 9.985, de 18 de julho de 2000, que dispõe sobre o Sistema Nacional de Unidades de Conservação da Natureza - SNUC, e dá outras providências. Decreto n. 4.340, de 22 de agosto de 2002. Disponível em 12/07/2019 em: http://www.planalto.gov.br/ccivil 03/decreto/2002/d4340.htm

Brasil (2000). Institui o Sistema Nacional de Unidades de Conservação da Natureza. Lei n. 9.985, de 18 de julho de 2000. Disponível em 12/07/2019 em: http://www.mma.gov.br/estruturas/sbf dap cnuc2/ arquivos/snuc.pdf

Brasil (2019). Portal da Legislação. Disponível em 12/07/2019 em: http://www4.planalto.gov.br/legislacao/

Delphim, C. F. M. (2004). O patrimônio natural no Brasil. IPHAN. Rio de Janeiro. Disponível em $12 / 07 / 2019$ em: http://portal.iphan.gov.br/uploads/publicacao/Patrimonio Natural no Brasil.pdf

Ministério do Meio Ambiente (2019). Relatórios de Unidades de Conservação do Cadastro de Unidades de Conservação (CNUC). Disponível em 12/07/2019 em: http://www.mma.gov.br/areas-protegidas/cadastro-nacional-de-ucs/consulta-gerarrelatorio-de-uc

Olivato, D., Gallo JR, H. (2008). Unidades de Conservação: conservando a vida, os bens e os serviços ambientais. São Paulo, Ministério do Meio Ambiente. Disponível em

$12 / 07 / 2019$

em: http://www.mma.gov.br/estruturas/pda/ arquivos/pri mc 061 pub car 001 uc.pd $\underline{f}$

ONU (1992). Convention on Biological Diversity. Disponível em 12/07/2019 em: https://www.cbd.int/doc/legal/cbd-en.pdf

Pereira, P. F.; Scardua, F. P. (2008). Espaços territoriais especialmente protegidos: conceito e implicações jurídicas. Revista Ambiente e Sociedade, Campinas, 11(1), 81-97. http://dx.doi.org/10.1590/S1414-753X2008000100007

Santiago, R. P. (2008). Memória e patrimônio cultural em ambientes virtuais. Dissertação. Mestrado em Arquitetura e Urbanismo, Ed. São Carlos: Universidade 
de São Paulo. Disponível em 12/07/2019 em: http://www.teses.usp.br/teses/disponiveis/18/18142/tde-10022008-144940/ptbr.php

Silva, C. R. (2008). Geodiversidade do Brasil: conhecer o passado, para entender o presente e prever o futuro. Rio de Janeiro: CPRM. Disponível em 12/07/2019 em http://rigeo.cprm.gov.br/xmlui/handle/doc/1210

Thomas, B. L., Foleto, E. M. (2013). A evolução da legislação ambiental no âmbito das áreas protegidas brasileiras. Revista Eletrônica do Curso de Direito da UFSM, 8(1), 734-745.

http://cascavel.ufsm.br/revistas/ojs-

2.2.2/index.php/revistadireito/article/view/8401/5090\#.Uq-ZWNJDv8s

IUCN (1994). Guidelines for Protected Area Management Categories. IUCN, Gland, Switzerland, and Cambridge, UK.

UNESCO. (1972). Convensão para a proteção do patrimônio mundial, cultural e natural. Conferencia Geral da Organização da Nações Unidas para Educação, a Ciência e a Cultura. Paris. Disponível em 12/07/2019 em: http://unesdoc.unesco.org/images/0013/001333/133369POR.pdf

UNESCO (2019). Patrimônio cultural no Brasil. Disponível em 12/07/2019 em: http://www.unesco.org/new/pt/brasilia/culture/world-heritage/cultural-heritage/

Zanirato, S. H. (2008). Desafios para a Convenção do Patrimônio da Humanidade diante das Mudanças Climáticas. Diez años de cambios en el Mundo, en la Geografía y en las Ciencias Sociales, 1999-2008. Anais del X Coloquio Internacional de Geocrítica, Universidad de Barcelona, Barcelona, 2008. Disponível em 12/07/2019 em: http://www.ub.edu/geocrit/-xcol/378.htm

Zanirato, S. H., Ribeiro, W. C. (2006). Patrimônio cultural: a percepção da natureza como um bem não renovável. Revista Brasileira de História, São Paulo, 26(51), 251-262. http://www.scielo.br/pdf/rbh/v26n51/12.pdf

Artigo recebido em/ Received on: 27/11/2019

Artigo aceite para publicação em/ Accepted for publication on: 30/12/2019 